\title{
Knowledge, Attitudes and Practices of Medical and Paramedical Staff in Blood Transfusion in the Democratic Republic of Congo
}

\author{
Jeff Maotela Kabinda1,2,3, Serge Ahuka Miyanga1, Philippe Donnen",5,6, Jeff Van den Ende" \\ Michèle-Wilmet Dramaix ${ }^{3,4,5}$ \\ ${ }^{1}$ Provincial Blood Transfusion Centre of Bukavu, Bukavu, Democratic Republic of Congo \\ ${ }^{2}$ Catholic University of Bukavu, Bukavu, Democratic Republic of Congo \\ ${ }^{3}$ Research Centre in Biostatistics and Epidemiology, Brussels, Belgium \\ ${ }^{4}$ Free University of Brussels, Brussels, Belgium \\ ${ }^{5}$ School of Public Health, Brussels, Belgium \\ ${ }^{6}$ Centre for Policy and Health Systems/International Health, Brussels, Belgium \\ ${ }^{7}$ Institute of Tropical Medicine, Antwerp, Belgium \\ Email: kabindaalu@yahoo.fr
}

Received 1 July 2014; revised 3 August 2014; accepted 16 August 2014

Copyright (C) 2014 by authors and Scientific Research Publishing Inc.

This work is licensed under the Creative Commons Attribution International License (CC BY).

http://creativecommons.org/licenses/by/4.0/

(c) (i) Open Access

\section{Abstract}

Objective: To assess the knowledge, attitudes and practices of providers in blood transfusion, HIV infections and hepatitis B and C in the province of South Kivu (eastern DRC). Methods: This study is comparative cross-sectional. It covered all the staff care. Our sample was composed by doctors, nurses, midwives, and agents' rapid training in activity in health sector in South Kivu between 1 December 2011 and 30 December 2011. Those medical and paramedical staffs came from 12 general reference hospitals, 11 hospitals and 65 health centers in the province of South Kivu. Three hundred and ninety three people were interviewed including $6.5 \%$ of physicians, $87.4 \%$ of nurses and $5.1 \%$ of midwives. Among them, $25.5 \%$ had received training in blood transfusion. Results: Overall, $11.7 \%$ of providers responded correctly to questions on knowledge and attitude on blood safety. The proportion of correct answers on the knowledge and attitude on exposure accidents was 53.8\%. The frequency of caregivers who responded well to the basics of HIV and hepatitis B and $\mathrm{C}$ was $15.5 \%$. Notions about the type of donor blood and the risk of blood transfusion received an overall rating of $\mathbf{1 7 . 8 \%}$ and the proportion of correct answers on the knowledge and practice base of blood transfusion was $16.7 \%$. During the six months following the survey, $54.4 \%$ of providers have experienced accidental exposure to blood. Conclusion: The lack of knowledge of the medical staff in transfusion is obvious. We must therefore have the possibility of organizing regular training and follow-up activities. 


\section{Keywords}

\section{Health Personnel, Transfusion, Hepatitis, HIV}

\section{Introduction}

In the administration of quality care, blood transfusion has a special place. It is a medical procedure, which aims to bring the patient's blood or its derivatives. It is the result of a complex chain of activities [1] during which involved various categories of medical and paramedical staff. Among the risks of blood transfusion, infectious diseases play an important part in Africa. This infectious residual risk can be attributed to four factors [2]: 1) technical error, most of the time human; 2) a viral variant not recognized by certain reagents; 3) a seronegative infectious donation in a chronic carrier; 4) a blood donation made in a recently infected individual ("silent window"). In addition to these risks, it may include transfusion errors in hospitals which are important between $1 / 6000$ and 1/30000 [3]. To get under control its means reducing risk and errors ought to redress by behavior of health worker and organizational factors. Those reducing factors are important in transfusion safety [4] [5]. Previous studies have shown that knowledge of health care providers was low in blood transfusion [3] [6]. In blood transfusion area in DRC efforts have been made by the establishment of a national policy, the implementation of blood centers in the provinces, and the outline of a quality assurance system. The challenge is enormous because the prevalence of infectious markers is still high-4.7\% for HIV, 3.7\% for syphilis and 5.4\% for HBsAg [7]. Hemovigilance system is nonexistent and basic training transfusion in the curricula of medical and other health personnel is insufficient or absent. Continuing education courses are dependent on funding and are very irregular. After all this training, an assessment has ever been made to identify their strengths and weaknesses in order to improve the quality and transfusion practices. This study aims to assess the knowledge, attitudes and practices of providers in blood transfusion, HIV infection and hepatitis B and C.

\section{Methodology}

\subsection{Type and Scope of the Study}

It is a comparative cross sectional study. It covered all the staff care doctors, nurses, midwives, agents rapid training (based in a health center) active in the hospital in South Kivu between 1 December 2011 and 30 December 2011. South Kivu province is in eastern DRC including 34 health zones located in 5 health districts (Bukavu, North, South, West and Central).

In 2011 the province had 5,536,118 inhabitants, 27 general hospitals reference, 595 health centers and a provincial hospital. The total staff of the province was 8051 agents among which noted in 7429 for health zones, 298 for the provincial hospital and 324 in the provincial health division. We noted 4471 administrative officers (56.6\%) and 3580 health professionals (44.4\%), including 392 doctors.

\subsection{Study Population}

The selection criterion was being practicing in health facilities in South Kivu. Based on a prevalence of knowledge and attitude of nursing staff in blood transfusion in Tunisia 15\% [3] and an accuracy of 5\%, the calculated sample size was 200 subjects. We raised 400 considering the sampling effect 2.

We used as a sampling frame is the list of health personnel based in South Kivu is situated in the provincial health division. For our investigation, we subtracted from the frame 1519 agents for 7 health zones inaccessible for reasons of safety or road, 324 agents of provincial health division. Thus on 6208 agents we made a random selection of Microsoft Excel from the number of each health staff on the list. We distributed 400 surveys items; we had 393 participants in 12 reference general hospitals, 11 hospitals and 65 health centers. These institutions were in 12 health zones: 1 zone in district health Bukavu, 4 in the North District 2 in the Western District, 2 in the center and one health zone in the Southern District.

\subsection{Materials}

The survey instrument used was a self-administered questionnaire previously developed by foreign teams [3] 
and adapted to the local context and the purpose of this study.

The questionnaire contains four categories of multiple-choice questions for each assertion and the answer was yes or no. Thus there were 278 statements (yes or no) and we expected to have 80 "yes" and 198 "no" answers. For the quality of responses and ease after the explanation of the questionnaire, respondents were assisted until the filling by investigators. Filling questionnaire took a maximum of one hour. Data was collected by directly after filling questionnaire.

\subsection{Statistical Analysis}

The analyzes were performed using the STATA software version 10. Proportions were used to describe all variables except age and number of years of experience for which the median, the percentiles 25 and 75 (P25-P75) were presented. The chi-square test of Pearson was used to compare proportions, the significance level used was 0.05 .

\section{Results}

Our sample was composed of providers of different categories; the dominant was that of nurses (87.4\%). Over $50 \%$ of professionals have over 5 years experience. The median age was 34 years and sex ratio M/F was 2 . Regarding basic training, $52 \%$ of respondents had a high school education, $37 \%$ of graduate and $5 \%$ were agents of rapid formation. Hundred providers or $1 / 4$ of the sample had received training in blood safety during the job. Of these 100 people, 44 were formed by the Provincial Blood Transfusion Centre, 47 by agents of some non-governmental organizations (NGOs) and 9 had the information at meetings of restitution by a peer who had followed training. These providers were from general hospitals or hospitals (Table 1).

\subsection{Knowledge, Attitudes and Practices in Blood Transfusion}

A low percentage of correct responses were obtained for knowledge of the clinical indications for blood transfusion in children and adults, paraclinical parameters for transfusion practice tests before transfusion and after transfusion. In addition we observed that the proportion of correct answer on the controls necessary to achieve before transfusion was $16.5 \%$. Knowledge retention period blood products had a good response rate to $28.4 \%$. These low proportions of correct responses were observed both in the service of the hospitals in those health centers (Table 2). Knowledge provider's hospitals and health centers on the person who decides the blood was satisfactory. The approach to be taken before a post transfusion reaction is known by more than $90 \%$ of agents of two types of health institutions. Among 385 respondents, 59.7\% knew ultimate control. Among those who knew the ultimate control, $29 \%$ knew the locus of control and $71 \%$ knew who was doing it. A statistically significant difference was observed between physicians and nurses in the knowledge of the clinical indication for transfusion in adults ( $\mathrm{p}<0.001$, physicians $48.3 \%$ vs paramedics $19.8 \%$ ) and the child ( $\mathrm{p}=0.009$, doctors $37.9 \%$ vs paramedics $18.1 \%)$, knowledge of the place in which the ultimate control was done ( $\mathrm{p}=0.04$, physicians $37.9 \%$ vs paramedics $21.1 \%$ ) and monitoring practices transfusion ( $\mathrm{p}=0.007$, physicians $82.8 \%$ vs paramedics $56.9 \%$ ). A statistically significant difference was also noted between the providers who have received training in blood transfusion and those who did not follow about "the level of knowledge of analysis to be done before transfusion" item ( $p=0.03 ; 16.0 \%$ vs $8.2 \%$ ), knowledge on the ultimate control ( $p=0.002 ; 72.7 \%$ vs $55.2 \%$ ) and practice exams to do after transfusion ( $\mathrm{p}=0.02 ; 4.0 \%$ vs $0.7 \%$ ). We did not observe significant differences between the proportions of correct responses on all items of basic knowledge on the blood transfusion service with a maximum of 5 years experience and those with more than 5 years.

\subsection{Knowledge about the Type of Donor Blood and Blood Transfusion Risks}

When asked about the type of systematically infectious markers sought on all blood $10.7 \%$ of respondents gave correct answers, $11.4 \%$ of hospitals providers and $9.5 \%$ of health workers from health centers. Twelve percent of providers had knowledge about the risks associated with blood transfusion and $4.3 \%$ were aware of the types of donors found in our country (Table 3). Between doctors and nurses in all it is not noted statistically significant difference between the proportions of providers which supply the right answers for the different categories of knowledge on the type of donor and the risks associated with blood transfusion while difference was noted between providers trained in blood transfusion and those who did not receive training in blood transfusion for 
Table 1. General characteristics of health care providers in South Kivu in 2011.

\begin{tabular}{|c|c|c|}
\hline & n & \% or median (25P - 75P) \\
\hline Sex & 390 & \\
\hline $\mathrm{F}$ & 124 & 31.8 \\
\hline M & 266 & 68.2 \\
\hline Age (year) & 388 & $34(27-40)$ \\
\hline$<30$ & 158 & 40.7 \\
\hline $30-40$ & 137 & 35.3 \\
\hline $40-50$ & 77 & 19.9 \\
\hline$>50$ & 16 & 4.1 \\
\hline Formation & 393 & \\
\hline Hostipal & 66 & 16.8 \\
\hline Health center & 160 & 40.8 \\
\hline General hospital of reference & 167 & 42.4 \\
\hline Provider category & 371 & \\
\hline Doctor & 29 & 6.5 \\
\hline Nurse & 340 & 87.4 \\
\hline Midwife & 20 & 5.1 \\
\hline Years of experience (year) & 379 & $6(3-11)$ \\
\hline $0-1$ & 51 & 13.5 \\
\hline $2-5$ & 137 & 36.2 \\
\hline $6-10$ & 86 & 22.7 \\
\hline$>10$ & 105 & 27.7 \\
\hline Basic training & 367 & \\
\hline university & 25 & 6.8 \\
\hline advanced & 135 & 36.8 \\
\hline secondary & 190 & 51.8 \\
\hline Agents rapid training & 17 & 4.6 \\
\hline Job training in blood transfusion & 392 & \\
\hline No & 292 & 74.5 \\
\hline Yes & 100 & 25.5 \\
\hline
\end{tabular}

Table 2. Proportion of providers who supplied the correct answers (233 hospitals and 160 health centers) to questions on basic concepts in blood (knowledge, attitude and practices transfusion).

\begin{tabular}{cccc}
\hline Items of issues & All providers & \multicolumn{2}{c}{ Providers } \\
& $\%$ & Hospitals & Health centers \\
\cline { 2 - 4 } Who should decide according to a blood transfusion in a patient & & $\%$ & $\%$ \\
\hline What are the clinical parameters for blood transfusions in adults & 81.7 & 85.2 & 76.6 \\
What are the clinical parameters for a blood transfusion in children & 21.6 & 27.9 & 12.7 \\
List paraclinical parameters for a blood transfusion & 19.3 & 25.3 & 11.4 \\
List the required exams before transfusing a patient & 20.1 & 20.5 & 19.6 \\
List the controls to be performed on receipt of blood product & 10.2 & 11.4 & 8.2 \\
Quote retention period of whole blood & 16.5 & 15.3 & 17.7 \\
Do you know the ultimate control pre transfusion & 28.4 & 36.6 & 17.1 \\
include the place of realization of ultimate control & $59.7^{*}$ & 60.5 & 59.2 \\
Who should be the ultimate control before transfusion & $28.7^{* *}$ & 34.1 & 19.4 \\
What are the procedures to follow in case of a transfusion reaction & $71.0^{* *}$ & 68.2 & 75.3 \\
How is monitoring a blood transfusion & 92.1 & 92.1 & 93.0 \\
What are the necessary tests after transfusion in patients & 58.5 & 58.5 & 57.6 \\
\hline
\end{tabular}

\footnotetext{
${ }^{*} \mathrm{n}=385,{ }^{* *} \mathrm{n}=230$.
} 
Table 3. Proportion of providers (233 hospitals and 160 health centers) providing the right answers to questions about the type of donor blood and blood transfusion risks.

\begin{tabular}{|c|c|c|c|}
\hline \multirow[t]{3}{*}{ Items of issues } & \multirow{2}{*}{$\begin{array}{c}\text { All providers } \\
\%\end{array}$} & \multicolumn{2}{|c|}{ Providers } \\
\hline & & Hospitals & Health centers \\
\hline & & $\%$ & $\%$ \\
\hline In our country which are infectious markers for screening blood transfusion unit & 10.7 & 11.4 & 9.5 \\
\hline What are the risks associated with blood transfusion & 12.2 & 9.6 & 15.8 \\
\hline According to you what are the types of blood donors found in our society & 4.3 & 6.1 & 1.9 \\
\hline $\begin{array}{l}\text { Among these donors which have more advantages in the direction of reducing } \\
\text { the risk of transmitting infections }\end{array}$ & 63.6 & 67.3 & 58.9 \\
\hline What do you think of blood transfusion using blood from a donor paid & 52.7 & 54.2 & 51.3 \\
\hline $\begin{array}{l}\text { Infectious markers among which are the subject of systematic screening } \\
\text { on any unit to be transfused which you seem unimportant }\end{array}$ & 17.8 & 18.8 & 15.8 \\
\hline
\end{tabular}

the knowledge of the types of blood donors found in our society $(10.0 \%$ vs $2.4 \%$; $p=0.001)$. The proportion of respondents who answered the question correctly "Among the markers that are the subject of systematic screening on any unit to be transfused which you seem unimportant" was statistically different depending on experience; those with experience of more than 5 years had given a good answer frequently than those with five years or less experience $(23 \%$ vs $14 \%$; $p=0.02)$.

\subsection{Knowledge and Practical of Basic HIV and Hepatitis B and C}

The proportion of caregivers in hospitals and health centers have provided good answers was satisfactory knowledge about HIV transmission and the causative agent of HIV, while we observed very low percentages of respondents who reported the correct answers on the knowledge of the transmission and agents of hepatitis B and C among personal prestant in hospitals or health centers (Table 4). Poor proportion of people answering correctly was noted at the level of knowledge of risk factors for hepatitis B and C and knowledge of the window with respectively $1.5 \%$ and $5.1 \%$. There was no influence of the type of provider on the responses on the basic knowledge of HIV and hepatitis B and C. providers trained in blood transfusion were more often correct answers than others on the agents' knowledge of hepatitis B and C.

\subsection{Knowledge and Attitude to Accidental Exposure to Blood among Health Professionals}

Of 334 respondents, 185 were stung (55.4\%) during the last 6 months of the survey no statistical difference in terms of categories of service or years of experience. Some providers have experienced an accident exposure by the bite, more than a third of health professionals have stung more than twice. The proportion of providers correctly answering questions about accidental exposure to blood was very low, especially at the level of knowledge of the existence of a system of protection in hospital institutions (3.1\%) (Table 5). The proportion of correct answers on the question "The best way to prevent exposure to HIV sting is recapping needles?” was 47. 8\%.

\subsection{Knowledge, Attitude and Practices on Blood Safety}

Generally the KAP on blood safety was low (Figure 1). This proportion was 10.1\% among staff of health centers and $12.7 \%$ of those hospitals. Knowledge was more common at the basics of HIV and hepatitis B and C, for the type of blood donors and the risk of blood transfusion as well as knowledge and practices based on blood transfusion.

\section{Discussion}

Quality assurance in blood transfusion system is a prospective and normative program, which involves all stakeholders in the transfusion process and aims to ensure the quality and safety of blood products delivered throughout the chain leading to their administration and ensure the completeness and quality of information related to transfusion process, the information involved in the traceability of blood products [8]. Assessment of 
Table 4. Proportion of providers (233 hospitals and 160 health centers) providing the right answers to questions about the basics of HIV and hepatitis B and C.

\begin{tabular}{|c|c|c|c|}
\hline \multirow[t]{3}{*}{ Items of issues } & \multirow{2}{*}{$\begin{array}{c}\text { All providers } \\
\%\end{array}$} & \multicolumn{2}{|c|}{ Providers } \\
\hline & & Hospitals & Health centers \\
\hline & & $\%$ & $\%$ \\
\hline The most important human transmission fluid HIV & 53.9 & 55.0 & 53.2 \\
\hline The causative agent of HIV & 95.7 & 95.2 & 96.8 \\
\hline The causative agent of HBV & 46.8 & 51.9 & 39.2 \\
\hline The causative agent of HCV & 23.9 & 23.6 & 24.7 \\
\hline Risk factors for hepatitis B or C & 1.5 & 0.4 & 3.2 \\
\hline Transmission of the agent of hepatitis B & 21.9 & 21.8 & 22.8 \\
\hline Transmission of the agent of hepatitis C & 19.6 & 19.2 & 20.9 \\
\hline Existence of the treatment of hepatitis $\mathrm{B}^{*}$ & 40.1 & 33.3 & 50.4 \\
\hline Existence of the treatment of hepatitis $C^{* *}$ & 39.2 & 34.7 & 45.9 \\
\hline Knowledge of the serological window ${ }^{* * *}$ & 5.1 & 3.9 & 7.0 \\
\hline Have received training on $\mathrm{HIV}^{* * * *}$ & 19.0 & 23.3 & 13.4 \\
\hline
\end{tabular}

${ }^{*} \mathrm{n}=319 ;{ }^{* *} \mathrm{n}=301 ;{ }^{* * *} \mathrm{n}=389 ;{ }^{* * * *} \mathrm{n}=390$.

Table 5. Accidents exposure to blood among health professionals $(\mathrm{n}=393)$.

During the last 6 months how many times did you stung $(n=344)$

Zero time

At least once

Frequency of accidental exposure during the last 6 months

$\begin{array}{ll}\text { At least one } & 63.2 \\ 2 \text { - } 3 \text { times } & 20.7\end{array}$

$\begin{array}{ll}\text { More than } 3 & 16.2\end{array}$

Existence in the care institution of a system of protection of occupational exposure $(\mathrm{n}=388)$

Knowledge of appropriate actions to be taken immediately after accidental exposure 17.3

Is it necessary to report an injection syringe $(\mathrm{n}=361)$

Is it necessary to report an exposure by the human fluid or blood $(\mathrm{n}=335)$

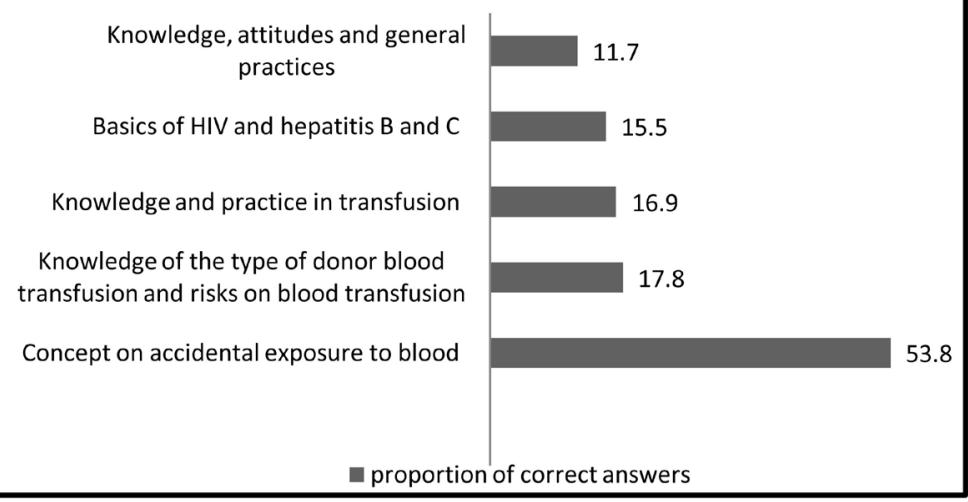

Figure 1. Proportion of health care providers in South Kivu who responded correctly to questions about different types of knowledge, attitudes and practices of blood transfusion. 
knowledge and practices of medical personnel in the field of blood transfusion is a prerequisite for reframe things in order to achieve the objectives of quality step. We conducted a study that aimed to assess the knowledge, attitudes and practices of providers in blood. The methodology applied in the construction of the sample could cause selection bias due to the exclusion of agents in areas less accessible health, those of the provincial hospital and those of the Health Division. This bias could be a problem in generalizing results and have an effect either in the direction of reduction or increase in certain proportions to certain questions. However the sample considered in this study reflects the photography throughout the province and the results give an overview of the problem. Our sample was composed of a majority of nurses and $6.5 \%$ of doctors. This is a picture of the distribution of health workers in the province of South Kivu where there is just $5 \%$ of physicians among them less than 30 specialists. The large number of nurses is due to a large number of hospital structures, requiring the presence of this category of staff in the administration of care [6]. Among caregivers, $25.5 \%$ had received training in blood transfusion during employment. This proportion is similar to that found by Diakite in Mali [6] (29.1\%). The little training of health personnel is due to lack of financial means of blood transfusion services. Continuous training in transfusion dependent financing of the health system in general and secondly of blood transfusion services. This funding is punctual dependent of NGOs and donors. Over $80 \%$ of providers said that it was the doctors who were prescribing blood transfusion while $18 \%$ said that the nurse could indicate transfusion. This result is different to that found by Pirie et al. who observed in Edinburgh 59\% of respondents supported the idea that nurses can prescribe blood transfusions [9]. Although the context of Edinburgh is different from ours and that blood transfusion is a medical procedure, but by delegation of tasks, nurses, in the interests of patient care and especially as the blood happens in emergency could indicate transfusion in the absence of physicians. Knowledge and practice basic blood was low in our study: $17 \%$ of providers had responded correctly. This was the same conclusion in Iran 22\%, Tunisia 15\%, Mali 37.6\% between 2\% and 56\% in Saudi and Canada 37\% [3] [10]-[15]. We noted a difference in knowledge between doctors and paramedical providers trained and those who did not receive training. Recent studies on blood transfusion suggest that improving knowledge and practice of transfusion medicine was essential and that the mastery of specific practices in the field of transfusion was based on transfusion knowledge of providers and led to the balance provisions and requirements of blood, and the correct performance of examinations before and after transfusion and a good monitoring of patients [6], [13] [16] [17]. For physicians, given the small number $(n=29)$ in our sample, we must consider carefully the difference between this category and paramedics. Nevertheless, our results indicate a direction to follow: the training of nursing staff is a necessity as it is a key link in transfusion safety. It should be provided for all newly employed in a care facility [6] [14] [17]. Saillour-Glenisson et al. [12] identified the factors responsible for the lack of knowledge and practice of blood transfusion in nursing: work in a hospital or services transfuse little, missing or incomplete information on blood safety and not have the information the hospital transfusion committee. In our study, the first factor and the third factor may explain the low knowledge as transfusion committees in hospitals are non-existent and most nurses do not work in the services transfuse. The second factor is difficult to sustain because the lack of knowledge and practice of blood transfusion was noticed even in groups of trained health personnel. This raises questions about the quality of these courses. Future studies should evaluate combining a qualitative and a quantitative approach with providers to identify the factors responsible for the observed lack of knowledge in the category of staff trained approach. Blood transfusion is a life-saving act, but who has many risks, including the risk of infection and is the result of the interventions of several actors whose blood donors. In our study, the risk of transfusion is only known by $12 \%$ of health workers while $11 \%$ know the tests for infectious markers and $4 \%$ type blood donors met in our society. The percentage of providers correctly answering questions about risk factors and mode of transmission of hepatitis B and C and the window period of HIV was very low even though the knowledge about the mode of transmission of HIV and its agent was excellent. This result suggests as other authors have suggested before us that the current training (initial and continuing) remains very poor [6]. In our survey $63.2 \%$ of providers have experienced at least once an accidental exposure to blood. Such large proportions have been reported in some studies 62.3\% in Morocco [18], 93\% in Nigeria [19]. Precautions used to prevent accidental exposure were not known and were far from being met in the institutions visited. But it is obvious that before requiring care personnel protective practices, it is the duty of the employer to make available protective equipment sufficient to promote the use of new, safer instruments, to train them to use to inform and sensitize permanently on the acts and gestures at risk [18]. On this point the training module on blood safety issued by the National Blood Transfusion Centre provides a chapter on safety which the notions of universal precautions are exempt. It is essential to know whether all these theoretical con- 
cepts learned are put into practice.

\section{Conclusion}

Our study, like other studies around the world, shows the lack of knowledge of the nursing staff on the basics of blood safety. The reasons for this weakness may be the lack of organization of the government department responsible for the coordination of transfusion in the country and the lack of organization of the medical staff education. The organization of continuous training in blood transfusion should be regular and improved. The supervision and monitoring of activities in facilities providing care must be made to ensure better administration of blood products to patients.

\section{References}

[1] Wautier, J.L. (1999) Evidence-Based Transfusion Medicine and Medical Training. Transfusion Clinique et Biologique, 6, 349-354. http://dx.doi.org/10.1016/S1246-7820(00)88979-X

[2] Pillonel, J. and Laperche, S. (2004) Trends in Residual Risk of Transfusion-Transmitted Viral Infections (HIV, HCV, HBV) in France between 1992 and 2002 and Impact of Nucleic Acid Testing. Transfusion Clinique et Biologique, 11, 81-86. http://dx.doi.org/10.1016/j.tracli.2004.02.004

[3] Letaief, M., Hassine, M., Bejia, I., Ben Romdhane, F., Ben Salem, K. and Soltani, M.S. (2005) Para Medical Staff Knowledge and Practice Related to the Blood Transfusion Safety. Transfusion Clinique et Biologique, 12, 25-29. http://dx.doi.org/10.1016/j.tracli.2005.01.002

[4] Miglot, V., Abelléa, P., Duédari, N., Besse-Moreau, M., Houssay, D. and Ingland, P. (2001) Regional Program to Improve Blood Transfusion Quality in Hospitals: Experience of Poitou-Charentes Area. Transfusion Clinique et Biologique, 8, 23-29.

[5] Mounic, V., Homs, J.B., Ledeon, V., Hamlin, P. and Loriferne, J.F. (1997) A Program of Continuous Quality Improvement of Blood Transfusion Safety: Example of St-Camille Hospital. Transfusion Clinique et Biologique, 4, 485-491. http://dx.doi.org/10.1016/S1246-7820(97)80066-3

[6] Diakité, M., Diawara, S.I., Tchiengoua Tchogang, N., Bfofana, D., et al. (2012) Connaissances et attitudes du personnel médical en matière de transfusion sanguine au Mali. Transfusion Clinique et Biologique, 19, 74-77. http://dx.doi.org/10.1016/j.tracli.2012.01.004

[7] Batina A., Kabemba, S. and Malengela, R. (2007) Infectious Markers among Blood Donors in the Democratic Republic of Congo (DRC). Revue Medicale de Bruxelles, 28, 145-149.

[8] Hergon, E., Moutel, G., Duchange, N., Bellier, L., Hervé, C. and Rouger, P. (2004) The Precautionary Principle Applied to Blood Transfusion. What Is Its Impact on Practices and Risk Management? Transfusion Clinique et Biologique, 11, 123-129. http://dx.doi.org/10.1016/j.tracli.2004.07.004

[9] Pirie, E. and Green, J. (2007) Should Nurses Prescribe Blood Components? Nursing Standard, 21, 35-41. http://dx.doi.org/10.7748/ns2007.06.21.39.35.c4565

[10] Clark, P., Rennie, I. and Rawlinson, S. (2001) Effect of a Formal Education Programme on Safety of Transfusion. British Medical Journal, 323, 1118-1120. http://dx.doi.org/10.1136/bmj.323.7321.1118

[11] Goodnough, L.T., Shander, A. and Brecher, M.E. (2003) Transfusion Medicine: Looking to the Future. Lancet, 361, 161-169. http://dx.doi.org/10.1016/S0140-6736(03)12195-2

[12] Saillour-Glénisson, F., Tricaud, S., Mathoulin-Pélissier, S., Bouchon, B., Galpérine, I., Fialon, P. and Salmi, L.R. (2002) Factors Associated with Nurses' Poor Knowledge and Practice of Transfusion Safety Procedures in Aquitaine, France. International Journal for Quality in Health Care, 14, 25-32. http://dx.doi.org/10.1093/intqhc/14.1.25

[13] Gharehbaghian, A., Javadzadeh Shahshahani, H., Attar, M., Rahbari Bonab, M., Mehran, M. and Tabrizi Namini, M. (2009) Assessment of Physicians Knowledge in Transfusion Medicine, Iran, 2007. Transfusion Medicine, 19, $132-138$. http://dx.doi.org/10.1111/j.1365-3148.2009.00923.x

[14] Hijji, B., Parahoo, K., Hussein, M.M. and Barr, O. (2013) Knowledge of Blood Transfusion among Nurses. Journal of Clinical Nursing, 22, 2536-2550. http://dx.doi.org/10.1111/j.1365-2702.2012.04078.x

[15] Rock, G., Berger, R., Pinkertn, P. and Fernandes, B. (2002) A Pilot Study to Assess Physician Knowledge in Transfusion Medicine. Transfusion Medicine, 12, 125-128. http://dx.doi.org/10.1046/j.1365-3148.2002.00363.X

[16] Tinmouth, A., MacDougall, L., Fergusson, D., Amin, M., Graham, I.D., Hebert, P.C. and Wilson, K. (2005) Reducing the Amount of Blood Transfused: A Systematic Review of Behavioral Interventions to Change Physicians' Transfusion Practices. JAMA Internal Medicine, 165, 845-852. http://dx.doi.org/10.1001/archinte.165.8.845

[17] Salem-Schatz, S.R., Avorn, J. and Soumerai, S.B. (1990) Influence of Clinical Knowledge, Organizational Context, 
and Practice Style on Transfusion Decision Making. Implications for Practice Change Strategies. JAMA, 264, 476-483. http://dx.doi.org/10.1001/jama.1990.03450040072034

[18] Laraqui, O., Laraqui, S., Laraqui, S., Tripodi, D., Caubet, A., Verger, C., et al. (2009) Évaluation des connaissances, attitudes et pratiques sur les hépatites virales B et C en milieu de soins au Maroc. Santé Publique, 21, 271-286.

[19] Olobuyide, I.O. and Olawuyi, F. (1995) Self Reported Incidence of Accidental Exposures to Patients’ Blood and Body Fluids by Resident Doctors in Nigeria. Perspectives in Public Health, 115, 235-243.

http://dx.doi.org/10.1177/146642409511500408 
Scientific Research Publishing (SCIRP) is one of the largest Open Access journal publishers. It is currently publishing more than 200 open access, online, peer-reviewed journals covering a wide range of academic disciplines. SCIRP serves the worldwide academic communities and contributes to the progress and application of science with its publication.

Other selected journals from SCIRP are listed as below. Submit your manuscript to us via either submit@scirp.org or Online Submission Portal.
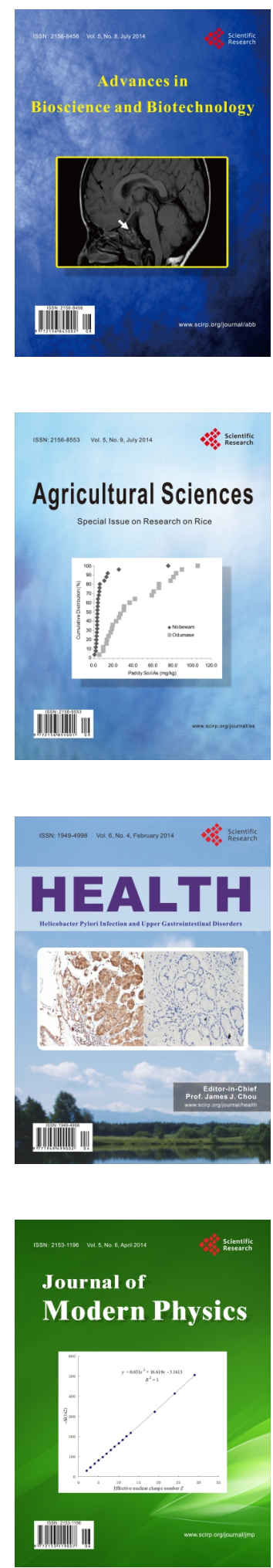
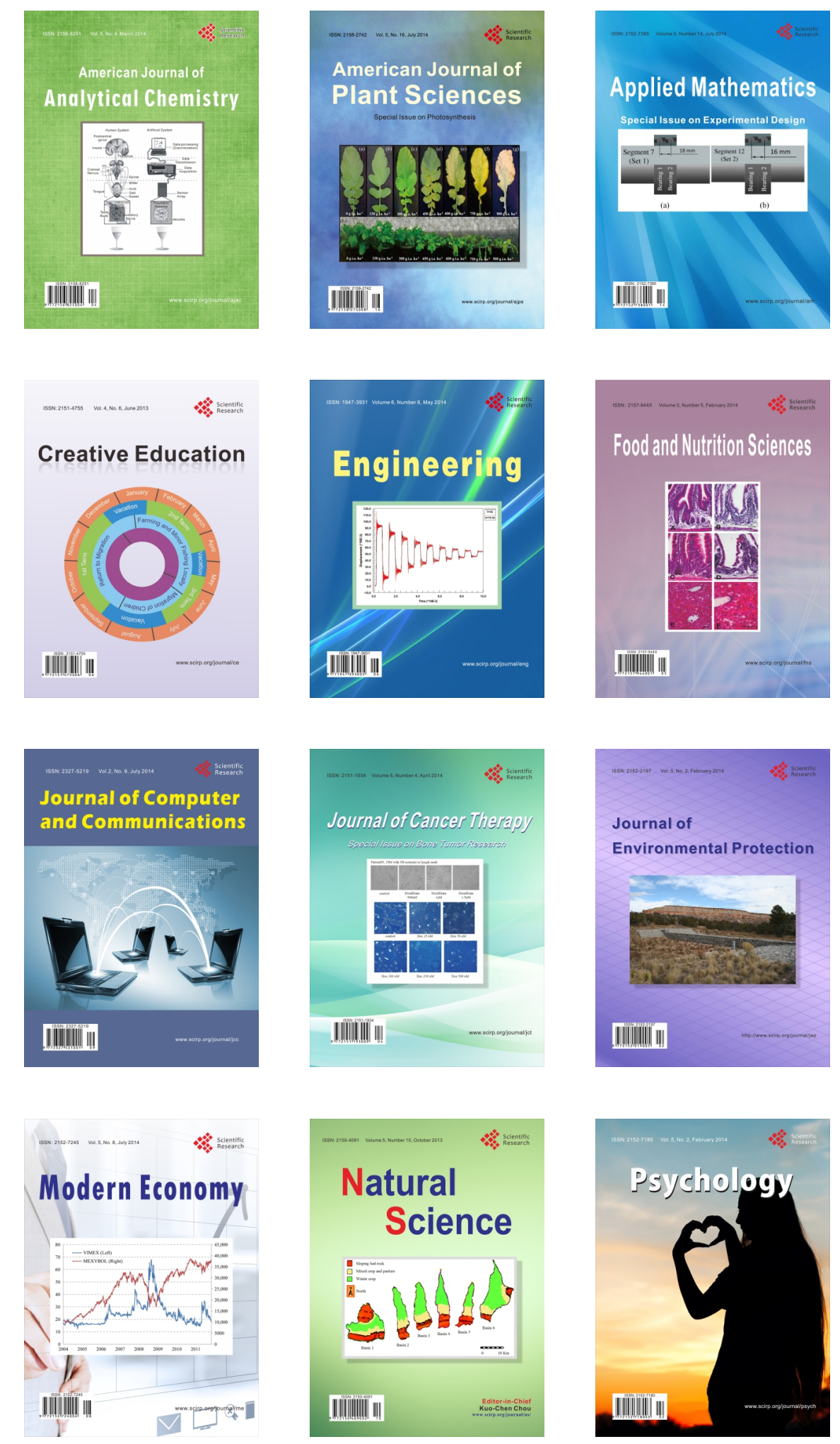